\title{
Impact of QT interval prolongation following antiarrhythmic drug therapy on left ventricular function
}

\author{
Konstantinos Chouchoulis ${ }^{*, 1}$, John Chiladakis', Nikolaos Koutsogiannis', \\ Periklis Davlouros', Maria Kaza² \& Dimitrios Alexopoulos ${ }^{1}$
}

\begin{abstract}
Aim: We assessed whether antiarrhythmic drug-induced QT interval prolongation affects left ventricular function. Methods: Study population included 54 patients with symptomatic recent onset atrial fibrillation spontaneously cardioverted to sinus rhythm. Electrocardiographic and echocardiographic studies were done before initiating and after achieving drug's steady state. Results: Significantly prolonged corrected QT interval (QTc) was noticed following only sotalol and amiodarone. The corrected precontraction time increased after sotalol $(p=0.005)$ and amiodarone $(p=0.017)$, not propafenone $(p=0.139)$. Analysis results between $\Delta \mathrm{EF}$ and $\Delta \mathrm{QTc}, \Delta \mathrm{EF}$ and $\Delta \mathrm{QTc}(\mathrm{p}), \Delta \mathrm{E} / \mathrm{e}^{\prime}$ and $\Delta \mathrm{QTc}, \Delta \mathrm{E} / \mathrm{e}^{\prime}$ and $\Delta \mathrm{QTc}(\mathrm{p})$ for amiodarone group were $(p=0.66, p=0.20, p=0.66, p=0.33)$, for sotalol $(p=0.36$, $p=0.51, p=0.44, p=0.33)$ and for propafenone $(p=0.38, p=0.12, p=0.89, p=0.61)$, respectively. Conclusion: QT interval prolongation following antiarrhythmic therapy does not affect significantly left ventricular function.
\end{abstract}

First draft submitted: 21 July 2016; Accepted for publication: 26 October 2016; Published online: 19 December 2016

Antiarrhythmic drugs (AADs) are frequently prescribed in everyday clinical practice for the management of atrial fibrillation (AF) that affects nearly $1-2 \%$ of the general population, reaching up to $11 \%$ in octagenarians [1,2]. The commonly used antiarrhythmics for AF rhythm control management belong to Vaughan Williams' classes, Ic and III. Both these medication categories are well known to: have an effect on ventricular depolarization and repolarization, alter QT and corrected QT interval (QTc) intervals on surface ECG and affect to variable extents the left ventricular (LV) function [3-9]. At cell level, cardiomyocyte's electrical activation initiates contraction and the duration of action potential defines myocyte's repolarization and cell's relaxation. Facts that indicate the close interaction between the electrical and mechanical components of heart's function. To the best of our knowledge, the impact of AADs on electromechanical coupling (time from electrical activation to initiation of LV contraction) and on mechanical activation sequence, has not been investigated extensively. In this prospective study we used newer echocardiographic techniques to assess the effect of AAD on electromechanical coupling and validate previously reported literature regarding their impact on LV systolic and diastolic function [10-17]. More importantly, we investigated for possible correlations between the effect of AAD therapy on QT interval, electromechanical coupling and LV function. The aim of this study was to evaluate if an easy to measure and accessible electrocardiographic parameter like QT interval could be used for early identification of patients at risk of LV function deterioration. Patients who would eventually benefit from closer clinical and echocardiographic monitoring.

'Cardiology Department, University Hospital of Patras, Rion, Patras, Greece

${ }^{2}$ School of Medicine, University of Patras, Rion, Patras, Greece

*Author for correspondence: kchouchoulis@gmail.com

\section{KEYWORDS}

- antiarrhythmic drug therapy • left ventricular function $\bullet$ QT interval prolongation 
Methods

- Patients

All patients with symptomatic recent onset AF $(<12 \mathrm{~h})$ presenting to the emergency department of our hospital were screened for participation in this study. All patients were anticoagulated initially with unfractionated heparin (1000 IU/h) and prescribed either a $\beta$-blocker or a rate limiting calcium channel blocker (e.g., diltiazem). Patients were monitored up to $24 \mathrm{~h}$ after their presentation for spontaneous cardioversion to sinus rhythm (SR). Study population who failed to revert to SR during the aforementioned time was excluded but offered pharmacological or direct current cardioversion therapy. Patients were also excluded if: they were already on class I or III antiarrhythmic medication; they were likely to have inherited long QT syndrome based on clinical criteria and family history; had signs of decompensated heart failure; and following inclusion to study, if they became unstable during the follow-up period; were intolerant to AADs or developed conduction abnormalities (Mobitz type II or higher) requiring discontinuation of AAD.

During 24 months, a total of 54 patients who fulfilled all the above mentioned criteria were included in the study. If they were on a $\beta$-blocker or rate limiting calcium channel blocker on admission, this was discontinued after their cardioversion to SR and before initiation of AAD. While on SR, patients were subjected to baseline electrocardiographic and echocardiographic studies. Subsequently, one of the indicated AADs for maintaining SR was commenced at the discretion of the initiating cardiology consultant, based on the European Guidelines for AF management [1]. Patients were eventually classified into three groups depending on the AAD initiated. The first group consisted of patients that were initially loaded orally with a total dose of $10 \mathrm{~g}$ of amiodarone, then continued with the maintenance dose $(208 \pm 62 \mathrm{mg} /$ day $)$ and scheduled to have a follow-up appointment at least 8 weeks after initiation of therapy. The second group was given sotalol $(260 \pm 66 \mathrm{mg} / \mathrm{day})$ and the third group, propafenone $(660 \pm 105 \mathrm{mg} /$ day $)$. Both second and third group patients were given an appointment after at least 4 weeks on antiarrhythmic maintenance dose. The appointments were scheduled after drug's five elimination half-lives (drug's steady state) had been reached. During the follow-up appointment, patients had to answer a standardized questionnaire to assess their compliance with AAD and have their pills counted. A standard 12-lead ECG and a transthoracic echocardiogram were also performed for each patient. LV systolic function was evaluated by both LV ejection fraction (LVEF) and global longitudinal strain (GLS) methods, whereas Doppler measurements (E/A and $\mathrm{E} / \mathrm{e}^{\prime}$ ratios) were used to assess LV diastolic function. The study was approved by the Ethics Committee of our hospital and all patients gave their informed consent prior to enrolment in the study.

\section{- Electrocardiographic measurements}

A MAC-VU ECG machine (Marquette Medical Systems, WI, USA) was used to record the 12-lead electrocardiograms at a paper speed of $25 \mathrm{~mm} / \mathrm{s}$ with a sensitivity of $10 \mathrm{~mm} / \mathrm{mV}$. The RR, PR, QRS and QT intervals were manually calculated by two blinded readers using a digital caliber (Mitutoyo Digimatic, IL, USA). The QRS complex was determined as the widest QRS interval in any lead from the initial QRS depolarization up to J point. Maximum QT interval (QTmax) was measured at the lead where it visually seemed longest and the end of $\mathrm{T}$ wave could be clearly defined. If the end point of the $\mathrm{T}$ wave was not clearly visualized then a straight line was drawn tangentially to it's descending part. The QTc was calculated using the Bazett heart rate correction method: QTc $=$ QT/ $(\text { RR interval })^{1 / 2}[18,19]$. If readers' calculations differed more than $5 \%$, then the mean value was adopted.

The difference of QTmax and QTc $(\Delta$ QTmax and $\Delta Q T c$, respectively) was calculated as:

- $\Delta$ QTmax = QTmax after achieving drug's steady state [QTmax(s)] minus baseline QTmax [QTmax (b)];

- $\triangle \mathrm{QTC}=\mathrm{QTc}$ after achieving drug's steady state [QTc(s)] minus baseline QTc [QTc(b)].

The proportion of $\Delta Q T$ max and $\Delta \mathrm{QTc}[\Delta \mathrm{QTmax}(\mathrm{p})$ and $\Delta \mathrm{QTc}(\mathrm{p})$, respectively] was calculated as:

- $\Delta \mathrm{QT} \max (\mathrm{p})=\Delta \mathrm{Q}$ Tmax divided by baseline QTmax [QTmax(b)];

- $\Delta \mathrm{QTc}(\mathrm{p})=\Delta \mathrm{QTc}$ divided by baseline QTc [QTc(b)].

\section{- Echocardiographic measurements}

The echocardiographic studies were performed using Vivid 7 (GE Healthcare, IL, USA) ultrasound scanner and analyzed by two trained physicians blinded to clinical data, using a 
workstation running the EchoPAC PC software. $2 \mathrm{D}$ echocardiographic measurements were done in accordance with the recommendations of the American Society of Echocardiography and the LVEF was assessed with the biplane method of disks (modified Simpson's rule) [20]. The mitral flow velocities (E, A) were assessed by Doppler flow velocity measurements.

Tissue Doppler imaging tracings were acquired by placing the region of interest on the medial and lateral corners of the mitral annulus at the apical four-chamber views. Three cardiac cycles were stored while the patient was holding his breath with a high image frame rate (above $100 \mathrm{fps}$ ). Both septal and lateral early peak diastolic velocities were measured and averaged $\left(\mathrm{e}^{\prime}\right)$ in order for $\mathrm{E} / \mathrm{e}^{\prime}$ ratio to be derived. Myocardial precontraction time (PCTm) was calculated as the time interval from the start of QRS to onset of systole at septal mitral annulus and used as index of mechanical activation (ventricular electromechanical coupling) [21].

Myocardial strain measurements using 2D Speckle Tracking technique were made with a minimum frame rate of $50 \mathrm{fps}$ [22]. The endocardial borders were manually traced at the endsystolic frame and the software automatically tracked myocardial speckles motion throughout the entire cardiac cycle. GLS was automatically calculated as the average of longitudinal maximum myocardial shortening from $16 \mathrm{LV}$ segments. If calculations made by the physicians differed more than $5 \%$, the mean value was taken.

Heart rate was recorded at the time of echocardiographic examination and PCTm was corrected for heart rate with the Bazett's formula: $\operatorname{PCTm}(\mathrm{c})=\operatorname{PCTm} /\left(\mathrm{RR}_{\text {interval }}\right)^{1 / 2}[19]$. The difference of $\operatorname{LVEF}(\triangle \mathrm{EF})$ and GLS $(\Delta \mathrm{GLS})$ were calculated by subtracting the baseline measurements (LVEF $[\mathrm{b}]$ and GLS [b], respectively) from the measurements done at the follow-up appointment (LVEF[s] and GLS[s], respectively). $\triangle \mathrm{PCTm}(\mathrm{c})$ was also defined as the PCTm(c) measured at the follow-up appointment minus the initial measured PCTm(c).

\section{- Statistical analysis}

Data are presented as mean \pm standard deviation for continuous variables and as a number (percentage) for categorical variables. Baseline characteristics of each group were analyzed by one-way analysis of variances, compared by chi-squared test and pairwise comparison
(Bonferroni test). Paired t-test analysis was used to compare the electrocardiographic and echocardiographic measurements done before the initiation of AAD therapy and at the follow-up appointment.

Pearson correlation coefficient ( $r$ ) was used to determine the strength of the relationship between the pairs of echocardiographic $(\Delta \mathrm{EF}, \Delta \mathrm{GLS}, \Delta \mathrm{E} / \mathrm{e}, \Delta \mathrm{PCTm}[\mathrm{c}])$ and electrocardiographic parameters $(\Delta \mathrm{QTmax}, \Delta \mathrm{QTc}$, $\Delta \mathrm{QTmax}[\mathrm{p}], \Delta \mathrm{QTc}[\mathrm{p}])$. Statistical significance and correlation between $\triangle \mathrm{PCTm}(\mathrm{c})$ and indices of LV systolic function ( $\triangle \mathrm{EF}, \Delta \mathrm{GLS})$ was also investigated. Characteristic curves were used to show the dependency of the studied parameters. A probability $\mathrm{p}$ value of $<0.05$ was considered statistically significant. Analyses were performed with SPSS software (Windows, Version 16.0, IL, USA).

\section{Results}

- Baseline \& follow-up characteristics

A total of 65 eligible patients (41 men and 24 women) were initially enrolled. Eleven patients $(17 \%)$ were excluded from the study: three from the group of amiodarone (due to severe photosensitivity $[n=1]$, severe bradycardia $[n=1]$ or declined follow-up appointment $[n=1]$ ), six from the group of sotalol (due to severely prolonged QTc above $500 \mathrm{~ms}$, after the initial doses $[n=3]$, hypotension $[n=1]$ or declined follow-up appointment $[\mathrm{n}=2]$ ) and two from the group of propafenone (one patient had an acute coronary event and one failed to maintain SR). 54 patients completed the study and their baseline characteristics are listed in Table 1.

Significant QTmax and QTc interval prolongation was noticed following sotalol (from $424 \pm$ $40 \mathrm{~ms}$ to $460 \pm 57 \mathrm{~ms}$ and from $446 \pm 35 \mathrm{~ms}$ to $474 \pm 48 \mathrm{~ms}$, respectively, both $\mathrm{p}<0.01)$ and amiodarone (from $437 \pm 41 \mathrm{~ms}$ to $504 \pm 39 \mathrm{~ms}$ and from $469 \pm 35 \mathrm{~ms}$ to $527 \pm 50 \mathrm{~ms}$, respectively, both $\mathrm{p}<0.01$ ), Table 2. Propafenone did not affect significantly the QTc interval (from $428 \pm 30 \mathrm{~ms}$ to $437 \pm 27 \mathrm{~ms} ; \mathrm{p}=0.147$ ). Changes at the rest of the electrocardiographic parameters (PR, RR, QRS) for all study populations were non significant, except the QRS duration at the group of amiodarone (from $126 \pm 33 \mathrm{~ms}$ to $135 \pm 33 \mathrm{~ms}, \mathrm{p}=0.037$ ).

The corrected myocardial precontraction time $(\mathrm{PCTm}[\mathrm{c}])$ was increased significantly following treatment with sotalol (from $97.4 \pm 21 \mathrm{~ms}$ to $108.4 \pm 20 \mathrm{~ms}, \mathrm{p}=0.005$ ) and amiodarone (from 
RESEARCH ARTICLE Chouchoulis, Chiladakis, Koutsogiannis, Davlouros, Kaza \& Alexopoulos

Table 1. Demographic and clinical characteristics of study population.

\begin{tabular}{|c|c|c|c|c|c|}
\hline Patient characteristics & All $(n=54)$ & Amiodarone $(n=14)$ & Sotalol $(n=30)$ & Propafenone $(n=10)$ & $p$-value \\
\hline \multicolumn{6}{|c|}{ Clinical characteristics \& medications } \\
\hline Age $(\text { years })^{+}$ & $69 \pm 10$ & $68 \pm 9$ & $69 \pm 10$ & $72 \pm 12$ & NS \\
\hline Women, n (\%) & $19(35)$ & $1(7)$ & $14(47)$ & $4(40)$ & $\begin{array}{l}\text { Propafenone and Sotalol }{ }^{\ddagger} ; \\
\text { Propafenone and Amiodarone }\end{array}$ \\
\hline CAD, n (\%) & $20(37)$ & $10(71)$ & $10(33)$ & $0(0)$ & NS \\
\hline CKD, n (\%) & $17(31)$ & $5(36)$ & $8(27)$ & $4(40)$ & NS \\
\hline HT, n (\%) & $42(78)$ & $13(93)$ & $22(73)$ & $7(70)$ & Propafenone and Sotalol ${ }^{\ddagger}$ \\
\hline DM, n (\%) & $14(26)$ & $4(29)$ & $9(30)$ & $1(10)$ & Propafenone and Sotalol ${ }^{\ddagger}$ \\
\hline LVEF $\geq 55 \%, n(\%)$ & $30(56)$ & $5(36)$ & $17(57)$ & $8(80)$ & Sotalol and Amiodarone ${ }^{\ddagger}$ \\
\hline ACEi/ATII, n (\%) & $34(63)$ & $11(79)$ & $17(57)$ & $6(60)$ & Propafenone and Sotalol ${ }^{\ddagger}$ \\
\hline Statin, n (\%) & $42(78)$ & $12(86)$ & $25(83)$ & $5(50)$ & $\begin{array}{l}\text { Propafenone and Sotalol }{ }^{\ddagger} ; \\
\text { Sotalol and Amiodarone }\end{array}$ \\
\hline OAC, n (\%) & $22(41)$ & $3(21)$ & $14(47)$ & $5(50)$ & $\begin{array}{l}\text { Propafenone and Sotalol }{ }^{\ddagger} ; \\
\text { Sotalol and Amiodarone }\end{array}$ \\
\hline \multicolumn{6}{|c|}{ Electrocardiographic values } \\
\hline Heart rate $(\mathrm{bpm})^{\dagger}$ & $68 \pm 10$ & $69 \pm 8$ & $67 \pm 11$ & $67 \pm 10$ & NS \\
\hline PR interval $(\mathrm{ms})^{\dagger}$ & $193 \pm 49$ & $216 \pm 54$ & $182 \pm 47$ & $192 \pm 39$ & NS \\
\hline QRS duration $(\mathrm{ms})^{\dagger}$ & $112 \pm 24$ & $126 \pm 33$ & $110 \pm 17$ & $97 \pm 20$ & Amiodarone and Propafenone \\
\hline $\mathrm{QTmax}(\mathrm{ms})^{\dagger}$ & $426 \pm 40$ & $437 \pm 41$ & $424 \pm 40$ & $410 \pm 33$ & NS \\
\hline QTc $(m s)^{\dagger \S}$ & $450 \pm 36$ & $469 \pm 35$ & $446 \pm 35$ & $428 \pm 29$ & Amiodarone and Propafenone ${ }^{\ddagger}$ \\
\hline \multicolumn{6}{|l|}{ Echocardiographic values } \\
\hline LV mass $(g)^{+}$ & $175.1 \pm 58.7$ & $213.9 \pm 73.9$ & $161.4 \pm 49.2$ & $161.7 \pm 37.8$ & Amiodarone and Sotalol ${ }^{\ddagger}$ \\
\hline LV mass index $\left(\mathrm{g} / \mathrm{m}^{2}\right)^{\dagger}$ & $90.8 \pm 27.5$ & $108.1 \pm 34.0$ & $85.1 \pm 23.9$ & $83.5 \pm 17.6$ & Amiodarone and Sotalol $^{\ddagger}$ \\
\hline $\mathrm{RWT}^{\dagger}$ & $0.35 \pm 0.08$ & $0.30 \pm 0.05$ & $0.38 \pm 0.09$ & $0.35 \pm 0.03$ & Amiodarone and Sotalol $^{\ddagger}$ \\
\hline LVEF $(\%)^{\dagger}$ & $54 \pm 08$ & $50 \pm 08$ & $50 \pm 08$ & $56 \pm 6$ & NS \\
\hline $\mathrm{E} / \mathrm{A}$ ratio $^{\dagger}$ & $1.08 \pm 0.57$ & $1.17 \pm 0.77$ & $1.02 \pm 0.52$ & $1.11 \pm 0.4$ & NS \\
\hline E/e' ratio $^{+}$ & $9.60 \pm 5.4$ & $10.25 \pm 7.98$ & $10.07 \pm 4.5$ & $7.29 \pm 2.37$ & NS \\
\hline $\mathrm{PCTm}(\mathrm{c})^{\dagger \S}$ & $102 \pm 24$ & $111 \pm 27$ & $97 \pm 21$ & $103.3 \pm 27$ & NS \\
\hline Global long strain (\%) $^{\dagger}$ & $-14.7 \pm 4.3$ & $-12.4 \pm 5.3$ & $-15.5 \pm 4.0$ & $-15.5 \pm 2.6$ & NS \\
\hline \multicolumn{6}{|c|}{$\begin{array}{l}\text { 'Mean } \pm \text { standard deviation. } \\
\text { 'Fignificant when } \mathrm{p}<0.05 \text {. } \\
\text { SValues corrected with the Bazett's formula. } \\
\text { ACEi: Angiotensin-converting enzyme inhibitor; AT II: Angiotensin II receptor antagonist; bpm: Beats per minute; CAD: Coronary artery disease; CKD: Chronic kidney with } \\
\text { eGFR <60 ml/min/1.73 m; DM: Diabetes mellitus; E/A: Early (E) to late (A) ventricular filling velocities; E/e': Early mitral inflow (E) and mitral annular early diastolic (e') velocity; } \\
\text { HT: Hypertension, LV: Left ventricle; LVEF: Left ventricular ejection fraction, NS: Nonsignificant; OAC: Oral anticoagulant; PCTm(C): Corrected myocardial precontraction time; } \\
\text { RWT: Relative wall thickness. }\end{array}$} \\
\hline
\end{tabular}

$111 \pm 27 \mathrm{~ms}$ to $125 \pm 34 \mathrm{~ms}, \mathrm{p}=0.017)$ Table 2 , but not for the group of propafenone (from $103 \pm$ $27 \mathrm{~ms}$ to $110 \pm 23 \mathrm{~ms}, \mathrm{p}=0.139)$. Changes at the rest of echocardiographic parameters $(\Delta \mathrm{EF}$, $\left.\Delta \mathrm{GLS}, \Delta \mathrm{E} / \mathrm{A}, \Delta \mathrm{E} / \mathrm{e}^{\prime}\right)$ were not significant for all study population ( $\mathrm{p}$-values of $0.89,0.12,0.97$, 0.54 , respectively) and for each individual group.

\section{- Correlations between}

electrocardiographic \& echocardiographic parameters

There was no significant correlation between all possible pairs of echocardiographic $(\Delta \mathrm{EF}$, $\left.\Delta \mathrm{GLS}, \Delta \mathrm{E} / \mathrm{e}^{\prime}\right)$ and electrocardiographic data [ $\Delta \mathrm{QTmax}, \Delta \mathrm{QTc}, \Delta \mathrm{QT} \max (\mathrm{p}), \Delta \mathrm{QTc}(\mathrm{p})]$ for the study population and each separate group.
Indicative correlations and characteristic curves are shown at Figure 1 and for all study population are between $\Delta \mathrm{EF}$ and $\Delta \mathrm{QTc}(\mathrm{p}=0.76 ; \mathrm{r}=0.04)$, $\Delta \mathrm{EF}$ and $\Delta \mathrm{QTc}(\mathrm{p})(\mathrm{p}=0.71 ; \mathrm{r}=0.05), \Delta \mathrm{E} / \mathrm{e}^{\prime}$ and $\Delta \mathrm{QTc}(\mathrm{p}=0.95 ; \mathrm{r}<-0.01), \Delta \mathrm{E} / \mathrm{e}^{\prime}$ and $\Delta \mathrm{QTc}(\mathrm{p})$ $(\mathrm{p}=0.99 ; \mathrm{r}<0.01)$. For the subgroup of amiodarone are between $\Delta \mathrm{EF}$ and $\Delta \mathrm{QTc}(\mathrm{p}=0.66$; $\mathrm{r}=-0.13), \Delta \mathrm{EF}$ and $\Delta \mathrm{QTc}(\mathrm{p})(\mathrm{p}=0.20 ; \mathrm{r}=-0.36)$, $\Delta \mathrm{E} / \mathrm{e}^{\prime}$ and $\Delta \mathrm{QTC}(\mathrm{p}=0.66 ; \mathrm{r}=0.13), \Delta \mathrm{E} / \mathrm{e}^{\prime}$ and $\Delta Q T c(p)(p=0.33 ; r=-0.28)$. Significance and correlations for the group of sotalol are between: $\Delta \mathrm{EF}$ and $\Delta \mathrm{QTc}(\mathrm{p}=0.36 ; \mathrm{r}=0.18)$, $\Delta \mathrm{EF}$ and $\Delta \mathrm{QTc}(\mathrm{p})(\mathrm{p}=0.51 ; \mathrm{r}=0.12), \Delta \mathrm{E} / \mathrm{e}^{\prime}$ and $\Delta \mathrm{QTc}(\mathrm{p}=0.44 ; \mathrm{r}=0.19), \Delta \mathrm{E} / \mathrm{e}^{\prime}$ and $\Delta \mathrm{QTc}(\mathrm{p})$ $(\mathrm{p}=0.33 ; \mathrm{r}=0.18)$ and for propafenone's group are between: $\Delta \mathrm{EF}$ and $\Delta \mathrm{QTc}(\mathrm{p}=0.38 ; \mathrm{r}=0.31)$, 
$\Delta \mathrm{EF}$ and $\Delta \mathrm{QTc}(\mathrm{p})(\mathrm{p}=0.12 ; \mathrm{r}=0.52), \Delta \mathrm{E} / \mathrm{e}^{\prime}$ and $\Delta Q T c(\mathrm{p}=0.89 ; \mathrm{r}=-0.05), \Delta \mathrm{E} / \mathrm{e}^{\prime}$ and $\Delta \mathrm{QTc}(\mathrm{p})(\mathrm{p}=0.61 ; \mathrm{r}=0.18)$.

\section{- Correlations between echocardiographic parameters}

Analysis of $\triangle \mathrm{PCTm}(\mathrm{c})$ and echocardiographic data assessing LV systolic function ( $\triangle \mathrm{EF}, \Delta \mathrm{GLS})$ for each of the three study groups came out non significant, except from the correlation between $\triangle$ PCTm(c) and $\triangle$ GLS for the group of sotalol $(\mathrm{p}=0.018 ; \mathrm{r}=0.42)$, a finding not matched with equal significance for the pair of $\triangle \mathrm{PCTm}(\mathrm{c})$ and $\Delta \mathrm{EF}(\mathrm{p}=0.35 ; \mathrm{r}=-0.17)$ at the same group of patients.

\section{Discussion}

The aim of this study was to investigate if the degree of AADs' provoked QT prolongation could be used as a simple parameter able to alert the clinician about a forthcoming deterioration of patient's LVEF. Our main findings may be summarized as follows: i) no statistical significant correlation was identified following AAD therapy between the prolongation of QTmax or QTc interval and LV systolic or diastolic performance; ii) for the groups of amiodarone and sotalol, the interrelation between the electrical and mechanical components of LV function (electromechanical coupling) was verified by statistically significant delay at the onset of myocardium contraction (PCTm $[\mathrm{c}]$ ); iii) LV function (assessed by LVEF, GLS and E/e') was not significantly affected by AAD treatment.

It is well known that AADs act on cardiomyocytes' ion channels, affect the concentration of cytosolic calcium and prolong the cell's action potential. At the organ level, AAD therapy may have an impact on two very important parameters of heart function: the duration of QTc interval and the mechanical performance of myocardium. The electrical component of AAD's impact (prolongation of QT and QTc intervals, measured in daily practice on surface ECG) is of major clinical importance as it is an independent prognostic factor for malignant ventricular tachyarrhythmias and sudden cardiac death $[3,4,23,24]$. In parallel, any alterations of $L V$ performance regardless of being a consequence of drug therapy or device therapy (cardiac resynchronization therapy) is another well known independent factor impacting on patient's morbidity and mortality [7-9].

Table 2. Effect of antiarrhythmic drugs on electrocardiographic and echocardiographic parameters.

\begin{tabular}{|c|c|c|c|c|c|c|c|c|c|}
\hline \multirow[t]{2}{*}{ Patient characteristics } & \multicolumn{3}{|c|}{ Amiodarone $^{\dagger}$} & \multicolumn{3}{|c|}{ Sotalol ${ }^{\ddagger}$} & \multicolumn{3}{|c|}{ Propafenone $e^{\S}$} \\
\hline & $\begin{array}{l}\text { Initial } \\
\text { evaluation" }\end{array}$ & Follow-up" & $p$-value & $\begin{array}{l}\text { Initial } \\
\text { evaluation" }\end{array}$ & Follow-up" & $p$-value & $\begin{array}{l}\text { Initial } \\
\text { evaluation" }\end{array}$ & Follow-up" & p-value \\
\hline Heart rate (bpm) & $69 \pm 8$ & $66 \pm 11$ & 0.475 & $67 \pm 11$ & $66 \pm 14$ & 0.668 & $67 \pm 10$ & $60 \pm 13$ & 0.092 \\
\hline PR interval (ms) & $216 \pm 54$ & $234 \pm 48$ & 0.073 & $182 \pm 47$ & $200 \pm 49$ & 0.152 & $192 \pm 39$ & $210 \pm 50$ & 0.09 \\
\hline QRS duration (ms) & $126 \pm 33$ & $135 \pm 33$ & 0.037 & $109 \pm 18$ & $114 \pm 23$ & 0.405 & $100 \pm 20$ & $200 \pm 25$ & 0.241 \\
\hline QTc (ms) & $469 \pm 35$ & $527 \pm 50$ & $<0.001$ & $446 \pm 35$ & $474 \pm 48$ & 0.008 & $428 \pm 30$ & $437 \pm 27$ & 0.147 \\
\hline \multicolumn{10}{|l|}{ Echocardiographic values } \\
\hline \multicolumn{10}{|l|}{ Conventional 2D: } \\
\hline \multicolumn{10}{|l|}{ Doppler data: } \\
\hline$-\mathrm{PCTm}(\mathrm{c})^{\#}$ & $111 \pm 27$ & $125 \pm 34$ & 0.017 & $97.4 \pm 21$ & $108.4 \pm 20$ & 0.005 & $103 \pm 27$ & $110 \pm 23$ & 0.139 \\
\hline \multicolumn{10}{|l|}{ 2D speckle tracking: } \\
\hline - Global long strain (\%) & $-12.4 \pm 5.3$ & $-11.8 \pm 4.8$ & 0.413 & $-15.5 \pm 4.0$ & $-16.4 \pm 3.5$ & 0.341 & $-15.5 \pm 2.6$ & $-16.2 \pm 2.6$ & 0.357 \\
\hline \multicolumn{10}{|c|}{$\begin{array}{l}\text { 'Maintenance dose of } 208 \pm 62 \mathrm{mg} . \\
\text { "Maintenance dose of } 260 \pm 66 \mathrm{mg} \text {. } \\
\text { 'Maintenance dose of } 660 \pm 105 \mathrm{mg} . \\
\text { 'Mean } \pm \text { standard deviation. } \\
\text { "Values corrected with the Bazett's formula. } \\
\text { bpm: Beats per minute; E/A: Early (E) to late (A) ventricular filling velocities; E/e': Early mitral inflow (E) and mitral annular early diastolic (e') velocity; LVEF: Left ventricular ejection } \\
\text { fraction; PCTm(c): Corrected myocardial precontraction time; QTc: Corrected QT interval; QTmax: Maximum QT interval. }\end{array}$} \\
\hline
\end{tabular}


RESEARCH ARTICLE Chouchoulis, Chiladakis, Koutsogiannis, Davlouros, Kaza \& Alexopoulos

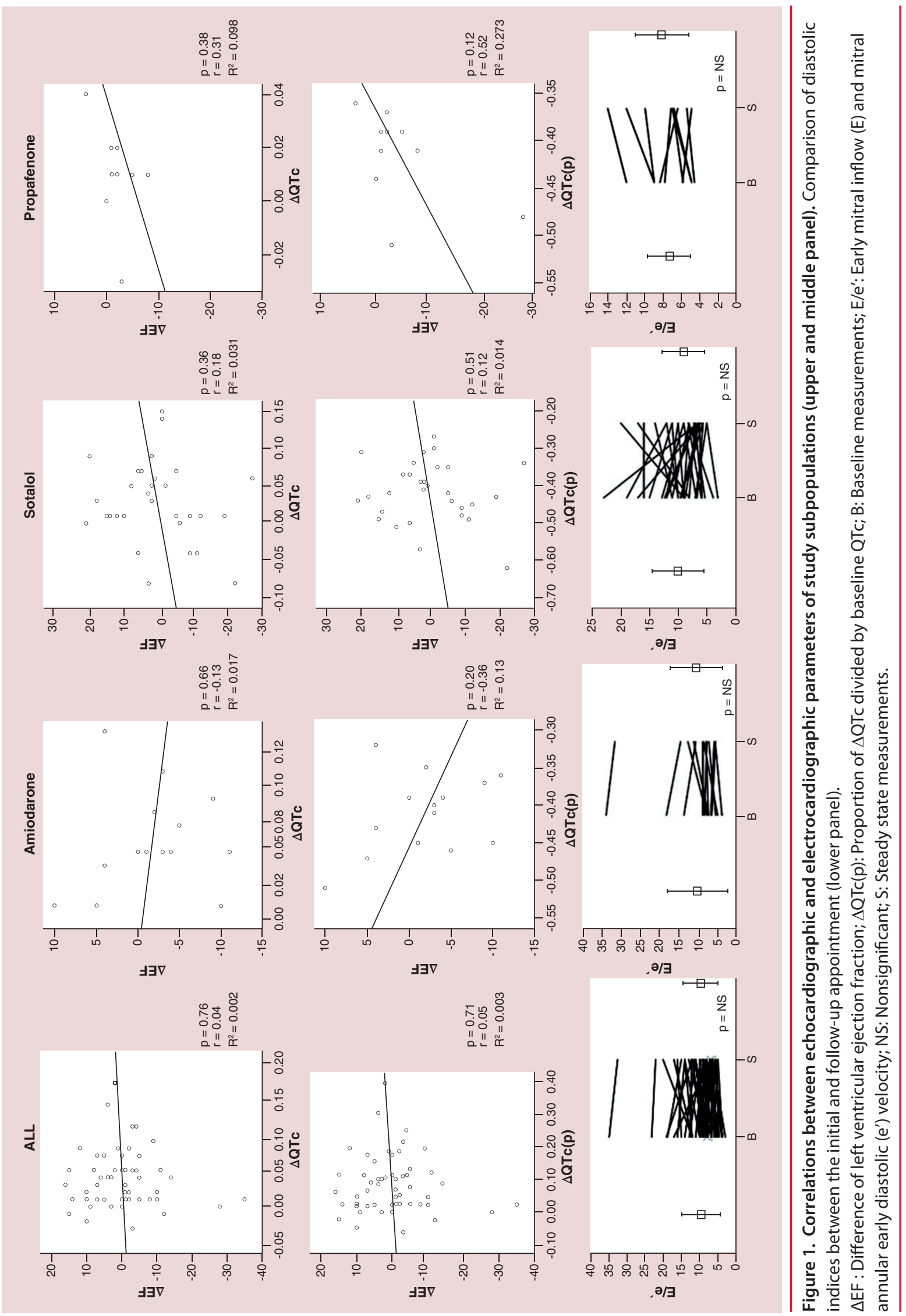


AADs affect directly ECG intervals as a result of their electropharmacological properties. Drugs of Ic Vaughan Williams classification category (e.g., propafenone) by decreasing the velocity of depolarization, can prolong the PR interval and QRS duration but have little effect on QT, particularly at rapid heart rates $[25,26]$. Class III AADs (e.g., sotalol, amiodarone) prolong repolarization and increase PR and QT intervals without increasing QRS duration (with the exception of amiodarone) [25].

The majority of AADs exert a negative effect on myocardium's contractile force, which consists an adverse effect especially important for patients with already reduced LV function. In detail, the use of class I AADs is expected to have negative inotropic effect due to their inhibitory effect on sodium channels [27,28]. Additionally, the antiarrhythmic properties of class II AADs ( $\beta$-blockers) are related to their antiadrenergic action which cause reduction to the cytosolic calcium and depress the force of contraction. On the contrary, the effect of pure class III AADs on potassium ion channels, by their propensity to prolong repolarization and calcium flux in cardiomyocyte are believed to augment contractility (positive inotropy) [13,29]. Finally, specific AADs (like propafenone, sotalol and amiodarone) have more complex pharmacological profiles with mixed class properties and different degrees of antiadrenergic action, features that affect their final impact on cardiac contractility.

Furthermore, cardiac function expressed usually as a percentage (LVEF) or a negative value (GLS) is proven to be a combined result of cardiac contractility and hemodynamic parameters, like LV preload and afterload [30]. In vivo studies targeted to assess AADs' consequences on cardiac function were done mainly during late 1980s, using echocardiography (ellipse biplane method was used in most of them to calculate LVEF) and gated radionuclide ventriculography $[11,14,16,17,31]$ Their main findings were: amiodarone caused a slight insignificant reduction to LVEF $[10,11,32,33]$, sotalol retained it unchanged $[13,14]$ and propafenone had a mild negative effect on LV systolic function [16,17,27]. To the best of our knowledge, no studies have addressed the impact of AADs on ventricular electromechanical coupling and the correlation of the latter with LV systolic function.

In our study as a consequence of commonly used AADs' doses, we noticed statistically significant prolongation for QTmax and QTc intervals following sotalol and amiodarone, whereas propafenone did not significantly affect QTc interval (Table 2). The statistically significant difference noted at the baseline population characteristics regarding QRS and QTc intervals (Table 1) between the groups of amiodarone and propafenone reflects the impact of European Guidelines on clinical decision making for AF management. Since patients with structurally intact heart (population with usually normal QRS, QTc) are prescribed propafenone and patients with more pathological cardiac background (more likely to have prolonged QRS, QTc) are prescribed amiodarone [1].

Precontraction time is usually used to assess inter- and intra-ventricular dyssynchrony identifying patients with higher risk of arrhythmias and sudden cardiac death, even at study groups with normal QRS duration. In our study we used the corrected for heart rate precontraction time to evaluate the effect of AADs on mechanical activation times and seek for possible interrelations between the electrical and mechanical components of $\mathrm{LV}$ activation. We found that the two study groups (of amiodarone and sotalol), which had significant prolongation of QT and QTc intervals had also significantly delayed LV activation time, implying a close interplay between these two parameters of heart's function.

In order to further assess if the noticed significant impact of AADs on QT intervals and on electromechanical coupling extends to dyssynchronous contraction and eventually reduced pump function, we used validated echocardiographic methods and GLS (2D Speckle Tracking technique) [20,30,34], to evaluate LV systolic function. Our results were in accordance with previous literature as: the amiodarone group exhibited a slight insignificant reduction of LV systolic function between the initial and the follow-up appointment, patients who were prescribed sotalol retained an unchanged LVEF and the group of propafenone experienced a non significant reduction of LV systolic function after drug's initiation.

Statistical analysis between the measured pairs of electrocardiographic and echocardiographic parameters did not reveal any significant correlation between them, indicating that the impact of AAD therapy on QT interval and electromechanical coupling is not related to changes noted at heart's systolic or diastolic performance. Our study validates physicians' current practice 
of using QTc values above $500 \mathrm{~ms}$ (as an index of increased arrhythmic risk) and clinical decompensation to decide for a dose reduction or discontinuation of AADs.

\section{Study limitations}

There were several limitations in the present study. Mainly, this study was not randomized and the sample size did not provide sufficient power to allow detection of statistical significance in more echocardiographic parameters or reveal more complex interrelations. We collected data for well-validated parameters such as $\mathrm{EF}, \mathrm{E} / \mathrm{A}, \mathrm{E} / \mathrm{e}^{\prime}$ that are included at the diagnostic algorithms of ESC and ASE to assess LV function, but we did not use newer promising parameters like early diastolic strain that may be used to detect more subtle alterations of heart's function. Additionally, we did not assess for interrelations between QT internal prolongation and right ventricular function.

Since stable patients with recent onset symptomatic AF were enrolled, patients with severe LV dysfunction were inevitably under-represented. We re-evaluated our patients between a period of 4 weeks to 2 months after their initial assessment, but an electrical effect as the noticed QT and QTc prolongation may need to be longer standing in order to have a significant impact on LV function. Finally, conclusions regarding electrical and mechanical inter-relations derived from the present study using AADs should not be generalized to every medication that can cause QT or QTc interval prolongation, as AADs have pleiotropic effects on cardiovascular system (e.g., $\beta$-blocker action, peripheral vasodilation) and do not affect only the ion channels and action potential [27].

\section{Conclusion}

QT and QTc interval prolongation following AAD therapy at commonly used therapeutic doses for treatment of atrial fibrillation does not seem to affect significantly the LV systolic or diastolic function.

Financial \& competing interests disclosure

The authors have no relevant affiliations or financial involvement with any organization or entity with a financial interest in or financial conflict with the subject matter or materials discussed in the manuscript. This includes employment, consultancies, honoraria, stock ownership or options, expert testimony, grants or patents received or pending or royalties.

No writing assistance was utilized in the production of this manuscript.

\section{Ethical conduct of research}

The authors state that they have obtained appropriate institutional review board approval or have followed the principles outlined in the Declaration of Helsinki for all human or animal experimental investigations. In addition, for investigations involving human subjects, informed consent has been obtained from the participants involved.

\section{Open access}

This work is licensed under the AttributionNonCommercial-NoDerivatives 4.0 Unported License. To view a copy of this license, visit http://creativecommons.org/ licenses/by-nc-nd/4.0/

\section{EXECUTIVE SUMMARY}

- The aim of this study was to investigate if the degree of antiarrhythmic drugs' (AAD) provoked QT prolongation could be used as a simple parameter able to alert the clinician about a forthcoming deterioration of patient's left ventricular ejection fraction.

- We studied 54 patients with symptomatic recent onset atrial fibrillation spontaneously cardioverted to sinus rhythm.

- Patients were subsequently subjected to electrocardiographic and echocardiographic studies before initiating and after achieving drug's steady state.

- We found that the two study groups (amiodarone and sotalol) that had significant prolongation of QT and QTC intervals after initiation of $A A D$, had also significantly delayed precontraction time validating the dynamic interrelation between the electrical and the mechanical sequence of activation (electromechanical coupling).

- Further statistical analysis between the measured pairs of electrocardiographic and echocardiographic parameters for all study population and for each separate group, did not reveal any significant correlation between them.

- We concluded that QT and QTc interval prolongation following AAD therapy at commonly used therapeutic doses for treatment of atrial fibrillation, does not seem to affect significantly the left ventricle systolic or diastolic function. 


\section{References}

Papers of special note have been highlighted as:

- of interest; $\bullet$ of considerable interest

1 European Heart Rhythm Association (EHRA), European Association for Cardio-Thoracic Surgery, Camm AJ et al. Guidelines for the management of atrial fibrillation: The Task Force for the Management of Atrial Fibrillation of the European Society of Cardiology (ESC). Eur. Heart J. 31(19), 2369-2429 (2010).

-• Dictates the current practice in management of patients with atrial fibrillation.

2 Vardas P, Andrikopoulos G, Baroutsou B, ODYSSEY Investigators. A Greek prospective observational study of cardiovascular morbidity and mortality in patients with atrial fibrillation. Hellenic J. Cardiol. 56(6), 475-494 (2015).

3 Shantsila E, Watson T, Lip GY. Drug-induced QT-interval prolongation and proarrhythmic risk in the treatment of atrial arrhythmias. Europace 9, iv37-iv44 (2007).

4 Kaufman ES, Zimmermann PA, Wang T et al. Risk of proarrhythmic events in the atrial fibrillation follow-up investigation of rhythm management (AFFIRM) study. J. Am. Coll. Cardiol. 44(6), 1276-1282 (2004).

5 Peters RW, Byington RP, Barker A, Yusuf S Prognostic value of prolonged ventricular repolarization following myocardial infarction: the BHAT experience. The BHAT Study Group. J. Clin. Epidemiol. 43(2), 167-172 (1990).

6 Straus SMJM, Kors JA, De Bruin ML et al. Prolonged QTc interval and risk of sudden cardiac death in a population of older adults. J. Am. Coll. Cardiol. 47(2), 362-367 (2006).

7 Cintron G, Johnson G, Francis G, Cobb F, Cohn JN. Prognostic significance of serial changes in left ventricular ejection fraction in patients with congestive heart failure. The V-HeFT VA Cooperative Studies Group. Circulation 87(Suppl. 6), VI17-VI23 (1993).

8 Kramer DG, Trikalinos TA, Kent DM, Antonopoulos GV, Konstam MA, Udelson JE. Quantitative evaluation of drug or device effects on ventricular remodeling as predictors of therapeutic effects on mortality in patients with heart failure and reduced ejection fraction. J. Am. Coll. Cardiol. 56(5), 392-406 (2010).

- Correlates drug- or device-related changes of patient's left ventricular ejection fraction and mortality.

9 Maeder MT, Ammann P. Changes in BNP and QTc for prediction of sudden death in heart failure. Future Cardiol. 9(3), 317-320 (2013).
- Correlates values of QTc and sudden cardiac death in heart failure patients.

10 Ammar A, Wong M, Singh BN. Divergent effects of chronic amiodarone administration on systolic and diastolic function in patients with heart disease. Am. J. Cardiol. 75(7), 465-469 (1995).

11 Trobaugh GB, Kudenchuk PJ, Greene HL et al. Effect of amiodarone on ventricular function as measured by gated radionuclide angiography. Am. J. Cardiol. 54(10), 1263-1266 (1984).

12 De Paola AA, Horowitz LN, Spielman SR et al. Development of congestive heart failure and alterations in left ventricular function in patients with sustained ventricular tachyarrhythmias treated with amiodarone. Am. J. Cardiol. 60(4), 276-280 (1987).

13 Hoffmeister HM, Beyer ME, Seipel L. Hemodynamic effects of antiarrhythmic compounds: intrinsic effects and autonomic modulation. Am. J. Cardiol. 80(8A), G24-G30 (1997).

14 Hohnloser SH, Zabel M, Krause T, Just H. Short- and long-term antiarrhythmic and hemodynamic effects of $\mathrm{D}$, $\mathrm{L}$-sotalol in patients with symptomatic ventricular arrhythmias. Am. Heart J. 123(5), 1220-1224 (1992).

15 Kroon W, Lumens J, Potse $\mathrm{M}$ et al. In vivo electromechanical assessment of heart failure patients with prolonged QRS duration. Heart Rhythm 12(6), 1259-1267 (2015).

16 Santinelli V, Arnese M, Oppo I et al. Effects of flecainide and propafenone on systolic performance in subjects with normal cardiac function. Chest 103(4), 1068-1073 (1993).

17 Baker BJ, Dinh H, Kroskey D, de Soyza ND, Murphy ML, Franciosa JA. Effect of propafenone on left ventricular ejection fraction. Am. J. Cardiol. 54(9), 20D-22D (1984).

18 Chiladakis J, Kalogeropoulos A, Arvanitis P, Koutsogiannis N, Zagli F, Alexopoulos D. Preferred QT correction formula for the assessment of drug-induced QT interval prolongation. J. Cardiovasc. Electrophysiol. 21(8), 905-913 (2010).

19 Bazett HC. An analysis of the time -relations of electrocardiograms. Ann. Noninvasive Electrocardiol. 2(2), 177-194 (1997).

20 Lang RM, Badano LP, Mor-Avi V et al. Recommendations for cardiac chamber quantification by echocardiography in adults: an update from the American Society of Echocardiography and the European Association of Cardiovascular Imaging. J. Am. Soc. Echocardiogr. 28(1), 1.e14-39.e14 (2015).
- Clarifies the standards for the echocardiographic assessment of left ventricular function.

21 Penicka M, Bartunek J, De Bruyne B. Improvement of left ventricular function after cardiac resynchronization therapy is predicted by tissue Doppler imaging echocardiography. Circulation 109(8), 978-983 (2004).

22 Geyer H, Caracciolo G, Abe $\mathrm{H}$ et al. Assessment of myocardial mechanics using speckle tracking echocardiography: fundamentals and clinical applications. J. Am. Soc. Echocardiogr. 23(4), 351-369 (2010).

23 Shah RR, Hondeghem LM. Refining detection of drug-induced proarrhythmia: QT interval and TRIaD. Heart Rhythm 2(7), 758-772 (2005).

24 Nielsen JB, Graff C, Rasmussen PV et al. Risk prediction of cardiovascular death based on the QTc interval: evaluating age and gender differences in a large primary care population. Eur. Heart J. 35(20), 1335-1344 (2014).

25 Surawicz B, Knilans TK. Chou's Electrocardiography in Clinical Practice (6th Edition). Surawicz B, Knilans TKand Chou TC (Eds). Elsevier Saunders, Philadelphia, PA, USA 511-512 (2008).

26 Vallurupalli S, Pothineni NVK, Deshmukh A, Paydak H. Utility of routine exercise testing to detect rate-related QRS widening in patients without structural heart disease on class Ic antiarrhythmic agents (flecainide and propafenone). Am. J. Cardiol. 116(5), 730-732 (2015)

27 Nawada T, Tanaka Y, Hirai S et al. Evaluation of negative inotropic and antiarrhythmic effects of class 1 antiarrhythmic drugs. Int. J. Clin. Pharmacol. Ther. 32(7), 347-355 (1994).

28 Seipel L, Hoffmeister HM. Hemodynamic effects of antiarrhythmic drugs: negative inotropy versus influence on peripheral circulation. Am. J. Cardiol. 64(20), J37-J40 (1989).

29 Wallace AA, Stupienski RF, Brookes LM, Selnick HG, Claremon DA, Lynch JJ. Cardiac electrophysiologic and inotropic actions of new and potent methanesulfonanilide class III antiarrhythmic agents in anesthetized dogs. J. Cardiovasc. Pharmacol. 18(5), 687-695 (1991).

30 von Spiegel T, Wietasch G, Hoeft A. Basics of myocardial pump function. Thorac. Cardiovasc. Surg. 46(Suppl. 2), 237-241 (1998).

31 Cleland JG, Dargie HJ, Findlay IN, Wilson JT. Clinical, haemodynamic, and 
RESEARCH ARTICLE Chouchoulis, Chiladakis, Koutsogiannis, Davlouros, Kaza \& Alexopoulos

antiarrhythmic effects of long term treatment with amiodarone of patients in heart failure. Br. Heart J. 57(5), 436-445 (1987).

32 Sheldon RS, Mitchell LB, Duff HJ, Wyse DG, Manyari DE. Right and left ventricular function during chronic amiodarone therapy. Am. J. Cardiol. 62(10 Pt 1), 736-740 (1988).

33 Ellenbogen KA, O’Callaghan WG, Colavita PG, Smith MS, German LD. Cardiac

function in patients on chronic amiodarone therapy. Am. Heart J. 110 (2), 376-381 (1985).
34 Yingchoncharoen T, Agarwal S, Popović ZB, Marwick TH. Normal ranges of left ventricular strain: a meta-analysis. J. Am. Soc. Echocardiogr. 26(2), 185-191 (2013). 